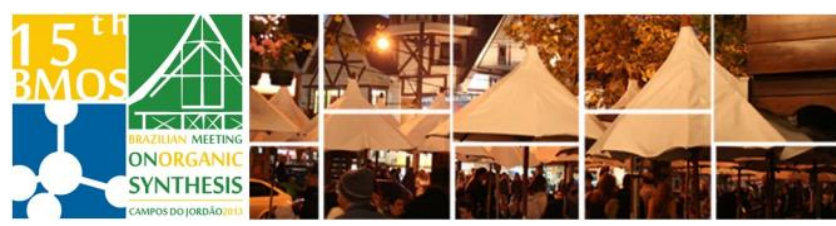

\title{
Chromenediones as potential plant growth regulators
}

\author{
Elson S. Alvarenga ${ }^{1}$, Francielly T. Souto', Vitor C. Baia' ${ }^{2}$, Maria Regina A. Gomes ${ }^{2}$ \\ ${ }^{1}$ Federal University of Viçosa, Chemistry Department, Viçosa, Minas Gerais, Brasil 36570-000 \\ ${ }^{2}$ UNIVICOSA, Avenida Maria de Paula Santana, no 3815 Bairro Silvestre - Viçosa, MG, Brasil 36570-000 \\ *e-mail corresponding author: elson@ufv.br
}

Keywords: chromenedione, herbicide, sesquiterpene lactones

\section{INTRODUCTION}

Sesquiterpene lactones (SLs) have in their skeleton fifteen carbons and constitute a group of compounds with several biological activities. Because of their wide spectra of biological activities related with their ecological role as defense compounds, we have selected chromenediones as one of the most promising candidates for further studies. According to IUPAC nomenclature chromene is a polycyclic organic compound formed from the fusion of a benzene ring to a heterocyclic pyran ring. $\alpha$ Santonin, a commercially available eudesmanolide, was employed as starting material for the synthesis of the chromenediones.

\section{RESULTS AND DISCUSSION}

Photosantonic acid (2) was prepared in $50 \%$ yield by irradiating $\alpha$-santonin (1) in a mixture of acetic acid and water $(2: 1)$ in a borosilicate reactor with two high pressure mercury lamps $(2 \times 125 \mathrm{~W})^{1,2}$. The first step for the formation of photosantonic acid is a $2+2$ cycloaddition followed by three rearrangements passing through lumisantonin and mazdasantonin. The stereochemistry of compound (2) was determined by $x$-ray data $a^{3,4}$. Reaction of photosantonic acid with either chlorine or bromine in dichloromethane afforded the chromediones (3) and (4) in 91 and $86 \%$ yield respectively. The proposed mechanism for the formation of chromenediones (3) and (4) from photosantonic acid is presented in scheme 1. The first step is the formation of the halonium followed by ring opening by attack of the carbonyl oxygen from the carboxylic acid.

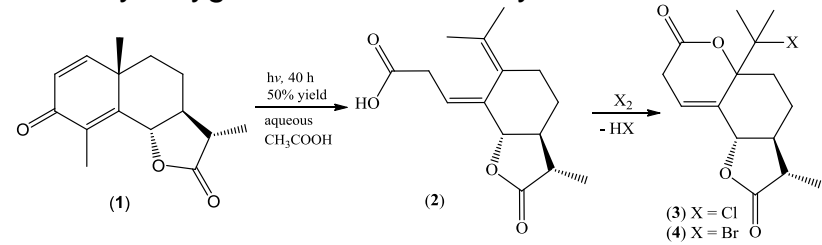

Scheme 1. Proposed mechanism for the formation of the chromenediones (3) and (4) from photosantonic acid.

The relative stereochemistry of the products were established by NOEDIFF experiments. In chromenedione 3, for example, a NOE enhancement was observed on $\mathrm{H} 8$ from $\mathrm{CH}_{3}$ (from the isopropyl group). When the other methyl group (from the isopropyl) is irradiated a NOE enhancement was observed on $\mathrm{H}-9 \mathrm{~b}$ and $\mathrm{H} 3$. All positive NOE effects are represented in the structure of compound 3 in Figure 1.

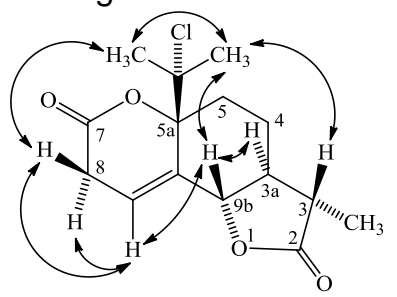

Figure 1. Representation of positive NOE interactions for chromenedione 3 .

\section{Bioassay}

We have employed the Coleoptiles's bioassay because it is a fast and sensitive bioassay to a wide range of bioactivities. Coleoptiles were obtained from 3-days-old wheat seedlings sown on $15 \mathrm{~cm}$ diameter Petri dishes fitted with Whatman filter paper and grown at $25{ }^{\circ} \mathrm{C}$ in the dark. Fractions were tested at $1000,500,300,150,30$, and $15 \mu \mathrm{M}$ in a nutritive aqueous solution ( $2 \%$ sucrose, IAA $\left.2.85 \times 10^{-7} \mathrm{~mol} / \mathrm{L}\right)$.

\section{CONCLUSION}

The presence of the a-methylene-y-lactone motif in sesquiterpene lactones is credited to be responsive for several biological activities. Thus we have prepared cromenediones with an electrophilic center (chlorine and bromine are good leaving groups) aiming to improve the biological potential. The strategy employed seems promising as we have observed 54 and $53 \%$ inhibition of coleoptile growth even at the concentration of $15 \mu \mathrm{M}$.

\section{ACKNOWLEDGEMENTS}

We would like to thank FAPEMIG for financial support and CNPq for the grant of FTS.

\section{REFERENCES}

Ferreira, J. R. O.; Cavalcanti, B. C.; Costa, P. M.; Arantes, F. F. P.; Alvarenga, E. S.; Maltha, C. R. A.; Barbosa, L. C. A. Toxicol. Vitro, 2013, 27, 1458.

${ }^{2}$ Alvarenga, E.S.; Silva, S.A.; Barbosa, L.C.A.; Demuner, A. J.; Parreira, A.G.; Ribeiro, R.I.M.A.; Marcussi, S. Toxicon, 2011, 57, 100.

${ }^{3}$ Asher, J. D. M.; Sim, G. A.; Proc. Chem. Soc. 1962, 111.

${ }^{4}$ Barton, D. H. R.; Miki, T.; Pinhey, J. T.; Wells, R. J.; Proc. Chem. Soc. $1962,112$.

$15^{\text {th }}$ Brazilian Meeting on Organic Synthesis - 15 $5^{\text {th }}$ BMOS - November 10-13, 2013 - Campos do Jordão, Brazil 